\title{
Needs for Consultancy of Vietnam high school students
}

\author{
Le Thi Quynh Nga \\ Vietnam National Institute of Educational Sciences. \\ Nguyen Huu Chau \\ Vietnam National University.
}

\begin{abstract}
This paper investigates the needs for consultancy of Vietnam high school students in resolving obstacles encountered in their academic and daily lives. Data are collected from a survey on 253 teachers and 1,089 students of 6 high schools in the urban and suburban areas (represented by Hanoi, Hochiminh City, and Thanh Hoa province) in the Northern, Southern and Central Region. It has been found that students face a range of difficulties on a regular basis and to different degrees. As such, they adopt certain solutions to specific issues. In this paper, teachers' consultancy is studied in order to figure out whether it is an option favored by students, and what they expect from teachers 'advice. Results show that although teachers are not hard to be reached, students rarely seek their advice since they hold higher expectations for consultancy than what their teachers can offer.
\end{abstract}

Keywords: Consultancy, Consulting teacher, Consultancy need, High school student

\section{INTRODUCTION AND LITERATURE REVIEW}

There exists a fact that more and more students are encountering difficulties at school and in their lives. This creates a need for consultancy, knowledge, and problem-solving skills in order for students to improve their academic performance and facilitate self-development.

In most schools in Vietnam, students can only seek advice from their teachers, who have a close relationship with them and a good understanding of the problems they are facing while learning at school. Teachers are also those having access to official sources of information and being able to educate and support their students in fulfilling academic tasks.

In his study, Carkhuff, R. R. (1968) [2] found that generally, many individuals in society receive advice from lay helpers rather than professional helpers. The support given by lay helpers usually emanates from humanity, sincerity, kindness and living experience. They wish to help people in need and those suffering from mental illnesses around them. Even when these helpers aim for personal interest, reputation, gratitude, or for the sake of their descendants, their support proves to be effective, philanthropically meaningful, and worth praising.

In the article entitled "The consulting teacher in the context of educational reform.", Pugach, M. C. (1988) [8] stated that professional teachers must know to combine in an excellent manner their profession as lecturers, and their role as instructors and consultants of students on every issue at school.

Beerens, D. R. (2000) [1], in "Evaluating teachers for professional growth: Creating a culture of motivation and learning" said that, in order to become professional, besides specialized knowledge and teaching skills, empathy is an important factor, which means teachers must 
consider themselves matured learners so as to help students overcome the same difficulties they used to face.

Based on ideas discussed above we can say that: Teacher consultancy competence is an attribute that was formed and developed by nature and during the learning process, allowing teachers to successfully fulfill the requirements of consultancy for students, achieve expected outcomes under specific conditions in order to effectively help in resolving problems faced by students during their study at school.

\section{A CASE STUDY ON CONSULTANCY NEEDS OF HIGH SCHOOL STUDENTS IN VIETNAM Objective of the research}

The study presented aims to investigate the difficulties in the academic and daily lives of high schoolers and their needs for consultancy on problem-solving so as to achieve good learning results and develop themselves.

Research Questions: This study is conducted in order to answer the following questions:

- What kinds of difficulties are frequently faced by high school students in the learning process and daily life, and how often do they encounter these problems?

- How do students overcome their obstacles?

- The need for consultancy and expectations from students?

\section{Research methods}

\section{Sampling}

Surveys are carried out on managers, teachers and students of grade 12 in 6 high schools in the urban and suburban areas in the Northern, Southern and Central Region of Vietnam (represented by Hanoi, Hochiminh City, and Thanh Hoa Province).

With the number of twelfth graders and their managers-teachers selected as subjects of investigation, we used Yamane Taro's (1967) [11] simplified formula for proportion

$$
\mathrm{n}=\quad \frac{\mathrm{N}}{1+\mathrm{N}(\mathrm{e})^{2}}
$$

In which (n) is the sample size, (N) is the total quantity, (e) is the standard error (the accuracy determined is $95 \%$, standard error $\mathrm{e}=+-5 \%$ )

Accordingly, the selected subjects of investigation are shown in the table below: 
Table 1: Subjects of investigation

\begin{tabular}{|l|c|c|c|c|}
\hline \multirow{2}{*}{ Name of school } & \multicolumn{2}{|c|}{ Overall quantity } & \multicolumn{2}{c|}{ Investigated subjects } \\
\cline { 2 - 5 } & $\begin{array}{c}12^{\text {th }} \\
\text { graders }\end{array}$ & $\begin{array}{c}\text { Managers- } \\
\text { Teachers of 12th } \\
\text { graders }\end{array}$ & $\begin{array}{c}12^{\text {th }} \\
\text { graders }\end{array}$ & $\begin{array}{c}\text { Managers- } \\
\text { Teachers of 12th } \\
\text { graders }\end{array}$ \\
\hline Xuan Dinh High School - Tay Ho District - Hanoi & 360 & 48 & 189 & 43 \\
\hline $\begin{array}{l}\text { Ngo Thi Nham High School - Thanh Tri District - } \\
\text { Hanoi }\end{array}$ & 345 & 51 & 182 & 45 \\
\hline Dao Duy Tu High School - Thanh Hoa Province & 317 & 42 & 177 & 38 \\
\hline $\begin{array}{l}\text { Hoang Le Kha High School - Ha Trung District - } \\
\text { Thanh Hoa }\end{array}$ & 290 & 41 & 170 & 38 \\
\hline $\begin{array}{l}\text { Nguyen Thi Minh Khai High School - District 3 - } \\
\text { Hochiminh City }\end{array}$ & 327 & 53 & 179 & 45 \\
\hline $\begin{array}{l}\text { Le Minh Xuan High School - Binh Chanh District } \\
\text { - Hochiminh City }\end{array}$ & 372 & 49 & 192 & 44 \\
\hline \multicolumn{1}{|c|}{ TOTAL } & $\mathbf{2 0 1 1}$ & $\mathbf{2 8 4}$ & $\mathbf{1 0 8 9}$ & $\mathbf{2 5 3}$ \\
\hline
\end{tabular}

(Source: Data collected from 6 high schools of sampling)

To gather opinions and assess high schoolers' needs for consultancy, 2 methods of data collection are adopted: quantitative and qualitative.

\section{Quantitative method:}

This method is used to collect data on the needs of consultancy of high school students. We develop the investigation tools including 02 sets of questionnaires targeting 02 subject groups: students; teachers and managers of high schools, aiming to identify problems frequently faced by high schoolers and their needs for support in addressing these issues.

\section{Qualitative method}

In order to collect, supplement and examine, and clarify the information provided by questionnaires, interviews and dialogues with a number of selected subjects were held.

\section{DATA COLLECTION AND DISCUSSION}

\section{Difficulties faced by high school students in academic and daily lives}

Survey results show that, among 5 aspects involving academic performance, communication and behaviors, gender-related issues, relationship with friends of opposite sex, career orientation and engagement in social activities, students find learning and choosing a career path the most concerning, and they have to suffer from academic pressure and exam stress $(M=3,93, S D=0,69)$; having career awareness and life orientations $(M=3,96, S D=1,16)$; identifying career interests and capabilities $(M=3,49, S D=1,19)$; choosing a pathway in line with one's capabilities, interests and conditions, as well as the needs of society. $(M=3,50$, $\mathrm{SD}=1,08)$.

Teachers hold the same view that students often struggle to perform academic tasks and find career paths. However, it is found that these obstacles are considered less serious by teachers than their students, which proves to be statistically significant. $(p<0,05)$. Specifically, teachers think that academic tasks and exams are the only two aspects deemed challenging by their students $(M=3,70, S D=0,58)$; career awareness and life orientations $(M=3,46, S D=0,89)$, while the rest are assessed as moderate difficulties $(M=2,68 \sim 3,32)$. This indicated that teachers have yet properly evaluated their students' concerns and their degree, which may make consultancy plans and methods unsuited to students' needs. 
Table 2 shows the frequency of students' facing difficulties as assessed by students and teachers.

Table 2: Frequency of students' facing difficulties in academic and daily lives

\begin{tabular}{|l|l|c|c|c|c|}
\hline \multirow{2}{*}{ No. } & & \multicolumn{2}{|c|}{ Difficulties } & Mean & \multicolumn{2}{|c|}{ SD } & Mean & SD \\
\cline { 3 - 6 } & & 3.33 & .931 & 3.10 & 0.93 \\
\hline 1 & Identifying learning motives, styles and competancy & 3.19 & 1.031 & 3.20 & 0.86 \\
\hline 2 & $\begin{array}{l}\text { Formulating learning plan, practicing learning skills and } \\
\text { methods }\end{array}$ & 3.12 & .866 & 3.24 & 0.74 \\
\hline 3 & Finding resources and support for learning & 3.93 & .687 & 3.70 & 0.58 \\
\hline 4 & Academic pressure and exam stress & 2.14 & 1.015 & 2.72 & 0.93 \\
\hline 5 & $\begin{array}{l}\text { My parents/teachers regard me as kids, treat me unfairly or do not } \\
\text { respect me }\end{array}$ & 2.52 & .971 & 3.02 & 0.94 \\
\hline 6 & My parents/teachers invade my privacy & 2.61 & .914 & 2.74 & 0.92 \\
\hline 7 & $\begin{array}{l}\text { My parents/teachers make assessments and judgments that I'm } \\
\text { dissatisfied with }\end{array}$ & 2.48 & 1.221 & 2.88 & 0.80 \\
\hline 8 & $\begin{array}{l}\text { My friends are jealous of me, talk behind my back, reject, isolate } \\
\text { me }\end{array}$ & 2.68 & 1.094 & 2.78 & 0.93 \\
\hline 9 & Lack of sympathy, sincerity, and sense of equality among friends & 2.21 & 1.071 & 2.88 & 0.96 \\
\hline 10 & $\begin{array}{l}\text { My friends tempt me to join gangs to do bad things (truancy, } \\
\text { smoking, fighting, etc.) and cover for one another }\end{array}$ & 2.35 & 1.087 & 2.94 & 1.10 \\
\hline 11 & Physical changes that arouse curiosity about gender & 3.31 & 1.293 & 3.06 & 1.08 \\
\hline 12 & $\begin{array}{l}\text { Treatment for common diseases, skincare for acne, personal and } \\
\text { genital hygiene }\end{array}$ & 3.50 & 1.076 & 3.32 & 1.06 \\
\hline 13 & Distinguish between friendship and romantic relationship & 3.18 & 1.384 & 3.22 & 0.79 \\
\hline 14 & $\begin{array}{l}\text { How to protect oneself in sexual relationship; How to control } \\
\text { oneself/reject sex-related request }\end{array}$ & 3.04 & 1.541 & 2.78 & 1.17 \\
\hline 15 & Career awareness and life orientations & 3.69 & 1.156 & 3.46 & 0.89 \\
\hline 16 & Career interests and capabilities & 3.49 & 1.192 & 3.20 & 1.11 \\
\hline 17 & $\begin{array}{l}\text { Understanding different career fields, labor markets and career } \\
\text { paths }\end{array}$ & 3.27 & 1.210 & 3.16 & 1.08 \\
\hline 18 & $\begin{array}{l}\text { Choosing a pathway suited to one's capabilities, interests and } \\
\text { conditions, as well as the needs of society }\end{array}$ & 2.77 & 1.259 & 3.08 & 0.97 \\
\hline 19 & Joining mass organizations, culture and sports clubs & 2.68 & 1.24 \\
\hline 20 & Participating in environmental cleanup & 2.15 & 2.98 & 0.98 \\
\hline 21 & Engaging in voluntary work, philanthropic activities & & & \\
\hline
\end{tabular}

(Source: Data collected and canculated by authors in survey 2019)

Academic performance is the most challenging aspect to twelfth graders in high schools. It is obvious that they are put under the greatest pressure of a life-changing examination. In a cultural context where diplomas and certificates are strongly favored, students are placed under considerable pressure, responsibility, and a state of anxiety that cannot be ceased until the university entrance exam ends with flying colors. According to the Ministry of Education and Training, only less than $30 \%$ of examinees are admitted to universities and colleges annually. Factual evidence has shown that there are 2 to 3 cases where students commit suicide due to failure in such entrance exam every year, and the number of patients with mental distress or depression because of the same reason also increases significantly. Among 4 academic obstacles mentioned, students feel stressful when taking exams more frequently than when trying to identify learning motives, styles, and capacity $(M=3,33, S D=0,93)$; making 
learning plans, practicing learning skills and methods $(\mathrm{M}=3,19, \mathrm{SD}=1,03)$; finding resources and support for learning $(M=3,12, S D=0,86)$. Although these difficulties are encountered with varied frequencies, there exists among them a correlation: exam stress is caused by the education system, yet greater stress may be created if students fail to identify the right motives, styles of learning. Hence, it is crucial to further study the relations among the obstacles faced by students so as to identify the root causes and give useful advice.

Another difficulty frequently faced by students is choosing career paths, which involves career awareness and life orientations $(M=3,69, S D=1,16)$; Choosing a pathway suited to one's capabilities, interests and conditions, as well as the needs of society $(M=3,50, S D=1,07)$; identifying career interests and capabilities $(M=3,49, S D=1,19)$. In fact, the career consultation work at the existing high schools proves to be ineffective. A number of students are unemployed or having jobs in the fields unrelated to their major, which is a waste of personal, household and social resources. One of the major causes is that little attention has been paid to career orientation activities at high schools. Most high school teachers have yet been trained to give instructions on career path selection and are not equipped with essential skills to help students choose the fields of working that suit their interests and capabilities. 3 out of 4 obstacles in the career aspect are considered frequently faced by students, whereas finding information on career fields, labor markets and career path development rarely is a challenge $(\mathrm{M}=3,27, \mathrm{SD}=1,21)$.

Regarding gender issues and relationships with friends of the opposite sex, difficulties in treating common diseases, caring for acne-prone skin, personal and genital hygiene $(M=3,31, S D=1,29)$; distinguishing between friendship and romantic relationship $(\mathrm{M}=3,18, \mathrm{SD}=1,28)$; protecting oneself in sexual relations, self-control/rejecting sex-related requests $(M=3,04, S D=1,54)$ recur occasionally. In general, students rarely find it hard to understand the changes in their bodies and the arousal of curiosity about gender. When being further interviewed, one student said that he/she did not have the need for consultancy on gender-related issues or maternity health "not because I am not facing any of these problems, but because information found on the internet is sufficient". However, that student was unable to name a few websites that he/she thinks are reliable. Though it is true that the internet provides humanity with unlimited sources of knowledge, students may face an inevitable risk of being misinformed if they have yet acquired adequate awareness and experience to identify official and reliable information. This has led to a number of consequences such as early sexual intercourse, pregnancy while attending school, abortion, dropout, etc.

In terms of social activeness, students occasionally experience difficulties when participating in mass organizations, culture and sports clubs $(\mathrm{M}=3,15, \mathrm{SD}=1,15)$; environmental cleanup $(M=2,79 ; S D=1,12)$; voluntary and philanthropic activities $(M=2,77, S D=1,26)$. However, a teacher said during a discussion that "It is true that high school students have their interest caught by a lot of matters other than social activities. However, it is of critical importance to help them become more socially active so that they can develop good qualities and avoid many other troubles in their academic and daily lives". Another teacher with the same view stated that "With than more than 20 years of experience in teaching high schoolers, I recognize that students have adopted a more positive attitude towards learning and better improved their academic performance as well as the relationship with others after engaging in social activities".

The least troubling aspect that rarely needs to be dealt with by students is communicating with family members, teachers and friends. Generally, the biggest issue to students is the assessment and judgment made by their parents or teachers $(M=2,61, S D=0,91)$; lack of sympathy, sincerity, and sense of fairness among friends $(M=2,68, S D=1,09)$. Disrespectful and unfair treatment, and 
invasion of privacy are rarely experienced by students; bullying, fighting, envy, hatred and hooliganism seldom occur. Nonetheless, an interviewed student reported that "My friends and I have had trouble communicating with teachers, family members, and classmates on a regular basis, yet I do not think it is so serious a problem that can affect my mental health, thus consultancy is not a need. I often talk to my friends when facing such issues".

As can be seen, students encounter a wide range of problems to different degrees, meaning an issue may seem more or less serious to certain individuals. Hence, the need for consultancy among students also varies. For instance, in terms of developing career awareness and life orientation, the frequency ranges from rarely to very often $(3,69 \pm 1,156)$.

In summary, high school students encounter a broad spectrum of difficulties in academic as well as daily lives. Normally, certain pressure and hardship are experienced by humans at each stage of life. As such, the major issues faced by twelfth graders whose lives are going to take a new direction include academic pressure, exam stress, and career orientations, about which they wish to be consulted the most. However, as reported directly by teachers and students, there exist other frequently faced issues that have influenced their two main focuses during this phase, namely learning and choosing a career path. In other words, each of the 5 categories mentioned has been considered an issue to students. They are correlative aspects that require consultancy and support so as to be addressed.

\section{The need for consultancy of students}

In order to further investigate the needs for consultancy of students at high schools and the necessity to organize counselling activities, another survey was carried out.

According to the results, most interviewed teachers and students said that the need for consultancy is considerable among students. However, the number of students having a compelling and very compelling need to be consulted was higher than assessed by teachers $(64,19 \%$ of students compared to $54 \%$ of teachers). As can be observed, students' real demands for receiving advice from teachers have yet been properly evaluated.

Similarly, nearly $2 / 3$ of surveyed students found it necessary and really necessary to organize counselling activities at high schools (64,29\%) and wished to be supported by teachers in handling academic and daily life difficulties $(69,05 \%)$. Although the proportion of teachers and students attaching crucial importance to consultancy was roughly equal $(65 \%)$, only $57 \%$ of teachers thought that their students would need advice from them. It is evident that teachers, despite having admitted the necessity to organize consultancy for students, have yet fully realized their roles in this activity.

Though having a great need for consultancy, very few students always $(1,19 \%)$ and frequently $(4,76 \%)$ seek support from teachers in addressing obstacles. More than half said that they never $(21,43 \%)$ or rarely (38.10\%) came to see teachers for help.

In summary, it is admitted by both teachers and students that consultancy activities need to be held at high schools and students really wish to be consulted by teachers, yet very few students actually reach teachers for advice. This once again an open relationship between these two groups has yet been established, hindering students from expressing their emotions and talking about their academic and daily life issues. 


\section{Students' expectation for teachers' consultancy}

When seeking teachers' consultancy, the expectations of students ranging from the highest to the lowest are as follows: Giving advice/direction to reasonably address the problem $(\mathrm{M}=3,93$, $S D=0,91)$; Ensuring confidentiality $(M=3,88, S D=1,06)$; Free of judgment $(M=3,69, S D=1,14)$; Having their voice raised and heard $(M=3,48, S D=1,09)$. Lower expectation (to a moderate degree) was held for finding support everywhere, everywhen and in every form $(M=3,35$, $S D=1,09)$. Despite that fact, some students who used to see their teachers for advice and felt satisfied to be consulted said that, meeting teachers outside the academic context and seeking help in several forms, rather than coming to the school's office, make it much easier for them to comfortably share their problems. This indicated that students wish to receive suitable advice, to keep their issues confidential, to be treated with no judgment, and able to reach teachers in any place, at any time, and in any way. Some students, despite having admitted their need for consultancy, hesitated to reach their teachers for fear that their expectations would not be met. In other words, it is essential that teachers at high schools enhance proper knowledge and skills to provide useful advice and follow principles to ensure the effectiveness of consultancy.

Survey results show that students expect the most to be given advice/direction for problemsolving $(M=3,62, S D=1,048)$, meanwhile teachers thought that students wish they could seek everywhere, every when in any form $(M=3,52, S D=0,814)$ - the same opinions were held by students on being further interviewed. For the three remaining aspects involving confidentiality, judgement-free and effective dialogue, the level of expectations held by students as assessed by teachers was moderate. It is clearly seen that the assessment made by teachers has yet corresponded with the expectations of students. This may lead to ineffective consultancy that fails to satisfy the students' needs and discourage them to reach teachers for help.

Table 3: Level of students 'expectation for teachers' consultancy

\begin{tabular}{|c|l|c|c|c|c|}
\hline \multirow{2}{*}{ No. } & \multicolumn{1}{|c|}{ Expectations } & \multicolumn{2}{|c|}{ Students } & \multicolumn{3}{c|}{ Teachers } \\
\cline { 3 - 6 } & & Mean & SD & Mean & SD \\
\hline 1 & Sharing issues and having their voice heard & 3.48 & 1.087 & 2.90 & 1.055 \\
\hline 2 & Preserving confidentiality & 3.88 & 1.064 & 3.34 & .895 \\
\hline 3 & Free of judgment & 3.69 & 1.146 & 3.32 & 1.039 \\
\hline 4 & $\begin{array}{l}\text { Being able to seek advice everywhere, every when, in } \\
\text { every possible way }\end{array}$ & 3.35 & 1.093 & 3.52 & .814 \\
\hline 5 & Being given useful advice/direction for problem-solving & 3.93 & .911 & 3.62 & 1.048 \\
\hline
\end{tabular}

(Source: Data collected and canculated by authors in survey 2019)

On being questioned to what degree they would follow the advice of qualified teachers, half of the students totally agree and agree (8.33\% and $41.67 \%$ respectively), almost one-fifth of them partly agree $(19,05 \%)$ and very few $(2,38 \%)$ disagree with their teachers. Similar question was given to teachers, and results show that they express higher confidence in their consultancy ability than expected by students: The majority of teachers either agree (46\%) or totally agree (15\%), and none of them neither disagrees nor partly agrees that students would act on their advice. This proves that teachers have yet brought into full play their potentials in counselling activities at high schools.

\section{CONCLUSION}

Nowadays, high school students frequently encounter several difficulties including academic activities, communication with others, gender-related issues, relationship with friends of the opposite sex, career orientation and involvement in social activities. The most concerning 
among those issues are academic performance and career orientation, since they are about to face the university entrance exam that may determine their coming future. Therefore, students have high needs for consultancy in order to handle such issues.

In fact, each student has his or her own way to solve problems. Results show that they tend to adopt a rather "introvert" approach, in other words to seek solutions on the internet or the media instead of sharing their issues with other persons. If students do talk about such issues, friends would be chosen as listeners as they seem to have a greater sense of sympathy and fairness. Meanwhile, it is shown in several studies that teachers can be a channel selected by a lot of students since they form a close relationship with students and understand students well in every aspect, especially those within the academic context. Moreover, teachers can gain access to trusted sources of information, and play a role in teaching and fulfilling students' academic tasks (Huefner, D. S. (1988); Christie, L. S., McKenzie, H. S., \& Burdett, C. S. (1972); Idol-Maestas, L. (1981); Pugach, M. C. (1988); Selvi, K. (2010)). The fact that students rarely seek teachers' advice indicates that an open relationship has yet been formed between these two groups, which hinders students from expressing their emotions and sharing their academic and daily life issues, and results in dissatisfaction with the consultancy provided by teachers.

In order to be trusted and be reached for help, consulting teachers need to satisfy their legitimate expectations as follows: Giving useful advice/direction to address problems; Ensuring confidentiality; Making no judgment; Listening to what they share; and Being available for support at any time, any place and in whatever way possible.

\section{References}

Beerens, D. R. (2000). Evaluating Teachers for Professional Growth: Creating a Culture of Motivation and Learning. Corwin Press, Inc., 2455 Teller Road, Thousand Oaks, CA 91320.

Carkhuff, R. R. (1968). Differential functioning of lay and professional helpers. Journal of Counseling Psychology, 15(2), 117-126

Dougherty, A. M. (1990). Consultation: Practice and perspectives. Thomson Brooks/Cole.

Gouvernement du Québec Ministère de l’Éducation (2004), Québec Education Program Secondary School Education, Cycle One, Legal Deposit-Bibliothèque nationale du Québec

Huefner, D. S. (1988). The consulting teacher model: Risks and opportunities. Exceptional Children, 54(5), 403414;

Idol-Maestas, L. (1981). A teacher training model: The resource/consulting teacher. Behavioral Disorders, 108121.;

OECD (2002), Definition and Selection of Competencies: Theoretical and Conceptual Foundation.

Pugach, M. C. (1988). The consulting teacher in the context of educational reform. Exceptional Children, 55(3), 273.

Selvi, K. (2010). Teachers' competencies. Cultura, 7(1), 167-175.

Steele, F. (1975). Consulting for organizational change. Univ of Massachusetts Press

Yamane, T. (1967). Statistics: An Introductory Analysis, 2nd Edition. New York: Harper and Row 